\title{
Predictors of thyroglobulin in the lymph nodes recurrence of papillary thyroid carcinoma undergoing total thyroidectomy
}

Zhichao Xing ${ }^{1 \dagger}$, Yuxuan Qiu ${ }^{1,2 \dagger}$, Zhe Li ${ }^{1}$, Lingyun Zhang ${ }^{1}$, Yuan Fei ${ }^{1}$, Jingqiang Zhu ${ }^{1}$ and Anping Su ${ }^{1 *}$ (e)

\begin{abstract}
Background: To investigate the association between postoperative lymph nodes (LNs) recurrence and distinct serum thyroglobulin (Tg) levels in patients with papillary thyroid carcinoma (PTC).

Methods: This study included PTC patients who underwent total thyroidectomy (TT) with at least central neck dissection and then re-operated due to recurrence of LNs between January 2013 and June 2018. These patients were grouped by negative or positive serum Tg levels according to the American Thyroid Association guidelines.

Results: Of the 60 included patients, 49 underwent radioactive iodine (RAl) treatment. Maximum unstimulated Tg $(\mathrm{uTg}) \geq 0.2 \mathrm{ng} / \mathrm{mL}$ were associated with larger diameter of recurrent LNs $(P=0.027)$, and higher rate of metastatic LNs $(P<0.001)$. Serum-stimulated Tg (off-Tg) $\geq 1 \mathrm{ng} / \mathrm{mL}(P=0.047)$ and unstimulated Tg (on-Tg) $\geq 0.2 \mathrm{ng} / \mathrm{Ml}(P=0.013)$ were associated with larger diameter of recurrent $L N s$. Number of metastatic $L N s \geq 8$ was an independent predictor for postoperative maximum $\mathrm{UTg} \geq 0.2 \mathrm{ng} / \mathrm{mL}(\mathrm{OR}=8.767 ; 95 \% \mathrm{Cl}=1.392-55.216 ; P=0.021)$. Ratio of metastatic $\mathrm{LNs} \geq 25 \%$ was an independent predictor for off-Tg $\geq 1 \mathrm{ng} / \mathrm{mL}(\mathrm{OR}=20.997 ; 95 \% \mathrm{Cl}=1.649-267.384 ; P=0.019)$.

Conclusion: Postoperative Tg-positive status was associated with larger size of recurrent LNs. Number of metastatic $L N s \geq 8$ and ratio of metastatic $L N s \geq 25 \%$ were independent predicators for uTg-positive and off-Tg-positive status, respectively.
\end{abstract}

Keywords: Thyroglobulin, Lymph nodes recurrence, Papillary thyroid carcinoma, Radioactive iodine treatment

\section{Background}

Papillary thyroid carcinoma (PTC) accounts for $85 \%$ of differentiated thyroid cancer and its incidence is rapidly growing worldwide [1]. PTC is often associated with lymph nodes (LNs) metastases in the central neck compartment (level VI) and then lateral neck compartment (level II to V) [2]. Total thyroidectomy (TT) with central neck dissection (CND) is often preferred as an

\footnotetext{
*Correspondence: suanpingping@126.com; 1300926572@qq.com

†'Zhichao Xing and Yuxuan Qiu contributed equally to this work

${ }^{1}$ Center of Thyroid \& Parathyroid Surgery, West China Hospital, Sichuan University, NO. 37 Guo Xue Xiang, Chengdu, Sichuan, People's Republic of China

Full list of author information is available at the end of the article
}

initial surgical procedure for patients with thyroid cancer $>4 \mathrm{~cm}$, or with gross extrathyroidal extension, or clinically visible metastatic disease to lymph nodes [1]. Selective or modified lateral neck dissection (LND) is performed under fine-needle aspiration cytology proven nodal metastasis [1]. Depending on the characteristics of the primary tumor and the risk of persistent or recurrent disease, postoperative radioactive iodine (RAI) can be necessary or recommended to prevent recurrence $[1,3]$. Occasionally recurrences were still seen even if the surgery and subsequent RAI treatment were assumed, and the risk factors for these recurrences were N1b patients with age $>55$ years or node metastasis $>3 \mathrm{~cm}[4]$. 
Serum thyroglobulin $(\mathrm{Tg})$ and anti-thyroglobulin antibody $(\mathrm{Tg} \mathrm{Ab})$ levels are recommended for assessing residual or recurrent diseases because the well-differential cancer or thyroid follicular cells are the only sources of serum $\mathrm{Tg}$ [1]. The serum Tg level is supposed to reach its lowest concentration at 3-4 weeks after TT. Therefore, $\mathrm{Tg}$ measurement from this point on is useful for detecting persistent or recurrent diseases [5]. Studies suggested the potential value of pre-RAI serum-stimulated Tg (off$\mathrm{Tg}$ ) on predicting recurrent diseases of metastatic PTC other than unstimulated Tg detected at 1 week after RAI ablation (on-Tg), although disputes still existed $[6,7]$. At the same time, recurrence of LNs is the most common form of residual or recurrent diseases, apart from distant metastasis and biochemical recurrence, which is detectable under regular ultrasound examination during follow-up [8]. However, the relationship between serum $\mathrm{Tg}$ levels and the risk of recurrence of LNs remained unclear. Some studies demonstrated that $\mathrm{Tg}$ measurement could possibly serve as a useful negative predictor of persistent and recurrent PTC [9], while other authors reported serum $\mathrm{Tg}$ levels cannot be considered as reliable indicators for the absence of disease in patients already treated with RAI [10].

Thus, the aim of this study was to investigate the $\mathrm{Tg}$ levels in PTC patients who developed LNs recurrence, thereby evaluating probable risk factors and structural features of LNs recurrence to assist clinicians in selecting optimal therapy and postoperative surveillance.

\section{Methods \\ Patients}

Clinical database containing 901 consecutive records of patients with PTC in the Center of Thyroid \& Parathyroid Surgery, West China Hospital, Sichuan University between January 2013 and June 2018 was reviewed. Patients with primary PTC who underwent TT and then re-operation due to LNs recurrence were included retrospectively. All surgeries were performed by one experienced surgeon team, and all recurrent LNs were confirmed by postoperative pathology. Tumors were staged according to the American Joint Committee for Cancer (AJCC) staging system (8th edition) [11]. Exclusive criteria included: (1) Patients underwent primary subtotal thyroidectomy or hemithyroidectomy and then recurred. (2) Patients did not undergo re-operations and no postoperative pathology were recorded. (3) Incomplete follow-up data. Proven or known thyroid remnant would be administered a therapeutic dose of radioactive iodine (RAI) dependent on outcomes of surgery in the next 1-2 months. Therefore, proven thyroid remnant was not exclusion criteria. This study was approved by the medical ethics committee of West China Hospital, Sichuan University.

\section{Treatments and follow-up}

The primary surgery for included patients was TT with ipsilateral CND (level VI). Therapeutic CND would be performed in patients with pathologically involved LNs. If the prelaryngeal or pretracheal lymph nodes were confirmed metastatic by intraoperative frozen section, contralateral prophylactic CND would be performed. For patients with lateral LNs metastases diagnosed by preoperative fine needle aspiration or on an intraoperative frozen section, therapeutic LND (level II-V) would be conducted. After primary surgery, intermediate and high risk level PTC patients according to the American Thyroid Association (ATA) risk stratification system and patients with proven thyroid remnant would be administered a therapeutic dose of RAI dependent on outcomes of surgery in the next 1-2 months [1].

Off-Tg and on-Tg levels were tested in patients receiving RAI therapy. Neck ultrasound, serum-free thyroxine, thyroid stimulating hormone (TSH), maximum unstimulated $\mathrm{Tg}$ (uTg, did not include on-Tg) and $\mathrm{TgAb}$ were tested every 3 months the first year, every 6 months for the second year, and thereafter annually[12].

\section{Definitions}

Off-Tg is defined as the Tg levels in condition of elevated TSH to $>70 \mathrm{IU} / \mathrm{ml}$ before RAI therapy and on-Tg is defined as the $\mathrm{Tg}$ levels in condition of thyroid hormone replacement after RAI therapy [1]. The maximum $\mathrm{uTg}<0.2 \mathrm{ng} / \mathrm{mL}$, on $-\mathrm{Tg}<0.2 \mathrm{ng} / \mathrm{mL}$ and off-Tg $<1 \mathrm{ng} /$ $\mathrm{ml}$ were deemed as negative $\mathrm{Tg}$ levels in the absence of interfering $\operatorname{TgAb}[1] . \operatorname{TgAb}>115 \mathrm{U} / \mathrm{mL}$ were considered positive TgAb levels in our center which could result in interference for $\mathrm{Tg}$ levels. All recurrent LNs were verified as structural recurrence with neck ultrasound. A fine needle aspiration was performed to confirm the recurrence and then a therapeutic neck dissection was performed in recurrent compartments.

\section{Groups and variants}

Patients were divided into two groups according to their $\mathrm{Tg}$ status. Groups were first set up by maximum uTg levels by a cut-off level of $0.2 \mathrm{ng} / \mathrm{mL}$. As for patients who were administered RAI therapy, they were divided into two groups by off-Tg with $1 \mathrm{ng} / \mathrm{mL}$ cut-off or by on-Tg with $0.2 \mathrm{ng} / \mathrm{mL}$ cut-off.

The following data were thoroughly reviewed: (1) Demographic data and basic information: age, sex, body mass index (BMI), nodular goiter (NG), hashimoto's thyroiditis (HD), hypertension, diabetes, hyperthyroidism. (2) Surgical outcomes: surgical extent and associated 
harvested LNs (number of LNs removed during reoperation), metastatic LNs, metastatic rate of LNs, and diameters of recurrent LNs. (3) Oncological data: tumor size, multifocality, bilaterality, TNM stage, extranodal extension.

\section{Statistical analysis}

Continuous variables were expressed as mean \pm standard deviation (SD). The $\chi^{2}$ test or Fisher exact test was used to evaluate the differences of incidences, and the student's $t$-test and/or analysis of variance was used to evaluate the differences of continuous variables. Based on the variables that were statistically significant or $P$ value $<0.25$ in univariate analysis, multivariate analysis with logistic regression was conducted to identify the independent risk factors. The variable was re-coded from a continuous variable into a dichotomous variable according to the optimal cut-off value produced by the receiver operator characteristic (ROC) curve analysis for multivariate analysis. The results of the multivariate analysis were reported as odds ratio (OR) with $95 \%$ confidence interval (CI). Two-sided $P<0.05$ was considered statistically significant. All statistical analyses were performed using IBM SPSS Statistics version 25.0 for Windows (IBM Corp., Armonk, NY).

\section{Results}

\section{Patient characteristics}

Sixty patients (18 males and 42 females) were included and the flow chart was displayed in Fig. 1. The mean age was $44.1 \pm 13.8$ years (interquartile range, IQR, $33-54$ years) and age $\geq 45$ and $\geq 55$ were seen in 29 $(48.3 \%)$ and 14 (23.3\%) patients, respectively. Eight (13.3\%) patients were considered as $\mathrm{TgAb}$-positive $(\mathrm{TgAb}>115 \mathrm{U} / \mathrm{mL})$. Forty-nine $(81.7 \%)$ patients underwent RAI therapy. The characteristics of the patients were presented in Table 1 . The mean size of the tumor was $21.7 \pm 14.3 \mathrm{~mm}$ and tumor diameter $>40 \mathrm{~mm}$ were found in $7(11.7 \%)$ patients. Multifocality and bilaterality were identified in $11(18.3 \%)$ and $8(13.3 \%)$ patients, respectively. T3 stage was found in $16(26.7 \%)$ patients while T4 in 19 (31.7\%) patients. The mean numbers of total harvested and involved LNs were $33.0 \pm 20.8$ and $8.5 \pm 8.2$, respectively.

\section{Follow-up}

During the follow-up with a median of 29 months (range, 13-78 months), central, lateral and both compartments LN recurrence were noted in 19 (31.7\%), 36 (60.0\%) and $5(8.3 \%)$ patients, respectively. The mean diameter of the largest recurrent LN was $18.7 \pm 12.9 \mathrm{~mm}$. Extranodal extension was observed in 20 (33.3\%) patients. All patients stayed alive till the end of follow-up.
Maximum uTg levels $\geq 0.2 \mathrm{ng} / \mathrm{mL}$ were detected in 42 (70\%) patients and maximum uTg levels $<0.2 \mathrm{ng} / \mathrm{mL}$ were found in 18 (30\%) patients during the follow-up. In 49 patients who underwent RAI treatment, 34 (69.4\%) had an off- $\mathrm{Tg} \geq 1 \mathrm{ng} / \mathrm{mL}$ and 15 (30.6\%) had an off- $\mathrm{Tg}<1 \mathrm{ng} /$ $\mathrm{mL}$, while on- $\mathrm{Tg} \geq 0.2 \mathrm{ng} / \mathrm{mL}$ and on- $\mathrm{Tg}<0.2 \mathrm{ng} / \mathrm{mL}$ were observed in $31(63.3 \%)$ and $18(36.7 \%)$ patients, respectively.

Meanwhile, in 52 patients with $\mathrm{TgAb}$-negative $(<115 \mathrm{U} /$ $\mathrm{mL}), 39(75.0 \%)$ and $13(25.0 \%)$ patients were appeared with maximum $u T g$ levels $\geq 0.2 \mathrm{ng} / \mathrm{mL}$ and $<0.2 \mathrm{ng} / \mathrm{mL}$ respectively (Table 2 ). Forty-three patients received RAI and $33(76.7 \%)$ of them had an off- $\mathrm{Tg} \geq 1 \mathrm{ng} / \mathrm{mL}$, and 10 (23.3\%) of them had an off- $\mathrm{Tg}<1 \mathrm{ng} / \mathrm{mL}$ (Table 3), while $30(69.8 \%)$ had an on-Tg $\geq 0.2 \mathrm{ng} / \mathrm{mL}$ and $13(30.2 \%)$ had an on- $\mathrm{Tg}<0.2 \mathrm{ng} / \mathrm{mL}$ (Table 4 ).

\section{Univariate analyses of factors associated with positive Tg levels}

The maximum $\mathrm{uTg} \geq 0.2 \mathrm{ng} / \mathrm{mL}$ were significantly associated with older age $(P=0.024)$, higher rate of diameters of recurrent LNs $\geq 25 \mathrm{~mm}(P=0.045)$ and higher LNs metastatic rate $(P=0.039)$, respectively. In 49 patients underwent RAI treatment, off- $\mathrm{Tg} \geq 1 \mathrm{ng} / \mathrm{mL}$ were significantly associated with older age $(P=0.042)$, larger diameter of recurrent LNs $(P=0.021)$ and higher rate of diameters of recurrent $\mathrm{LNs} \geq 25 \mathrm{~mm} \quad(P=0.038)$, respectively. Older age $(P=0.017)$, larger diameter of recurrent LNs $(P=0.020)$ and higher rate of diameters of recurrent LNs $\geq 25 \mathrm{~mm}(P=0.008)$ were also seen in patients with on-Tg $\geq 0.2 \mathrm{ng} / \mathrm{ml}$. However, lower rate of multifocality of the primary tumor was found in patients with off- $\mathrm{Tg} \geq 1 \mathrm{ng} / \mathrm{mL}(P=0.047)$ and on $-\mathrm{Tg} \geq 0.2 \mathrm{ng} / \mathrm{ml}$ $(P=0.039)$, respectively.

When excluding TgAb-positive patients, the maximum uTg levels $\geq 0.2 \mathrm{ng} / \mathrm{ml}$ were significantly associated with larger diameter of recurrent LNs $(P=0.027)$, higher rate of diameters of recurrent $\mathrm{LNs} \geq 25 \mathrm{~mm}(P=0.023)$ and higher LN metastatic rate $(P<0.001$; Table 2$)$. In the 43 patients with $\mathrm{TgAb}$-negative who underwent RAI treatment, off- $\mathrm{Tg} \geq 1 \mathrm{ng} / \mathrm{mL}$ was significantly associated with larger diameter of recurrent LNs $(P=0.018)$ and higher rate of diameters of recurrent $\mathrm{LNs} \geq 25 \mathrm{~mm}(P=0.047$; Table 3). Larger diameter of recurrent LNs $(P=0.020)$, higher rate of diameters of recurrent $\mathrm{LNs} \geq 25 \mathrm{~mm}$ $(P=0.013)$, and lower rate of multifocality $(P=0.032)$ were also seen in patients with on- $\mathrm{Tg} \geq 0.2 \mathrm{ng} / \mathrm{mL}$ (Table 4).

\section{Independent predictors of positive Tg levels}

In multivariate analysis, the number of metastatic LNs $\geq 8$ was an independent predictor for maximum $\mathrm{uTg} \geq 0.2 \mathrm{ng} / \mathrm{mL}$ in patients with $\mathrm{TgAb}$-negative 
Total patients diagnosed as PTC

$$
\text { ( } n=901)
$$

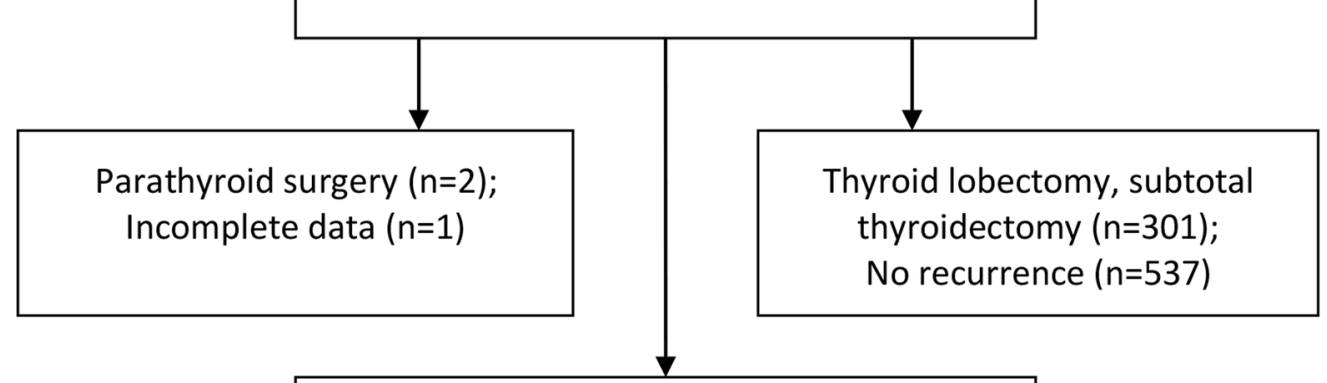

$\mathrm{TT}$ with reoperation due to $\mathrm{LNs}$ recurrence ( $n=60$ ), 52 of them with TgAb-negative

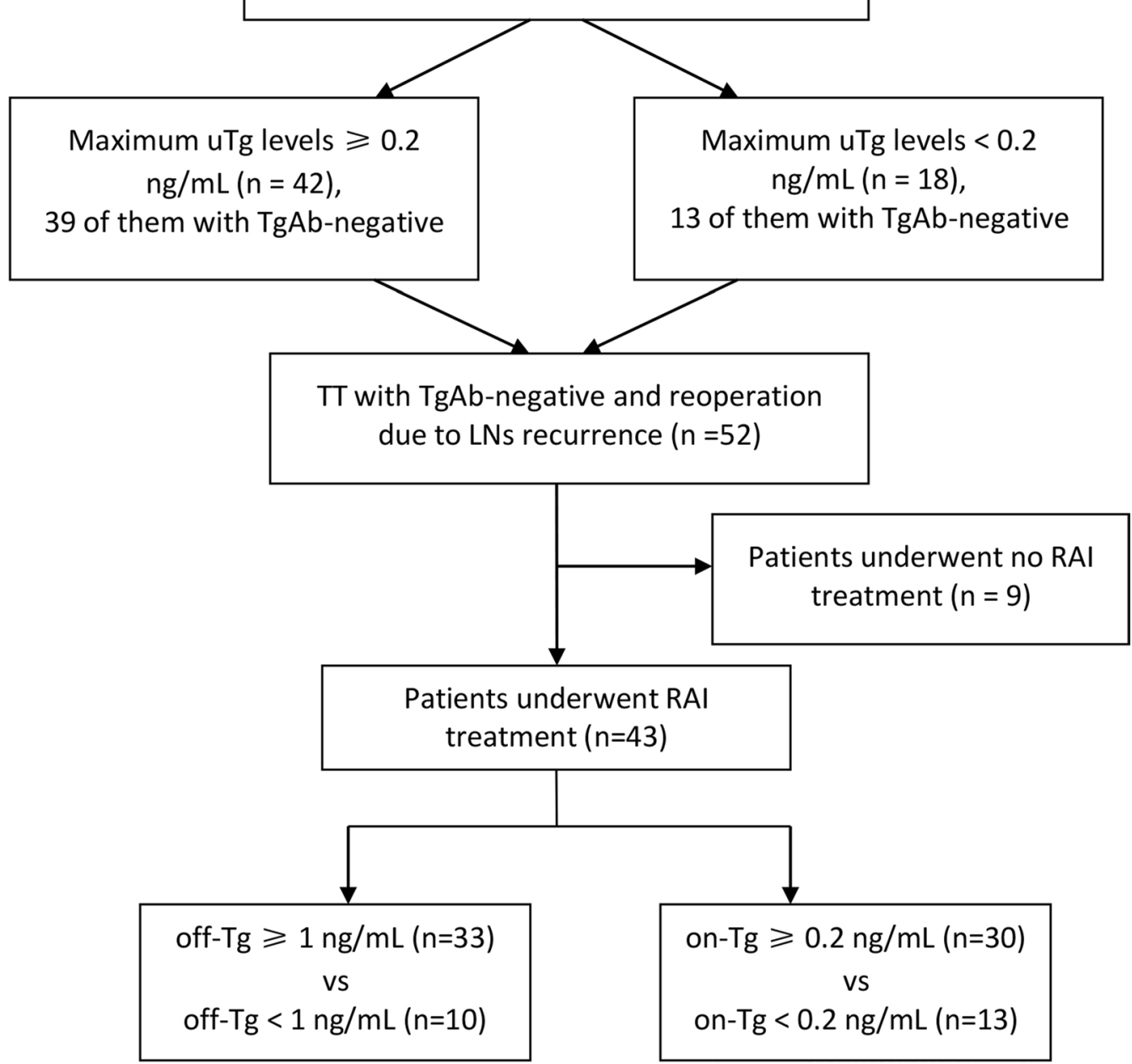

Fig. 1 Flow chart of patients reviewed. PTC papillary thyroid carcinoma, TT total thyroidectomy, LNs lymph nodes, Tg thyroglobulin, TgAb anti-thyroglobulin antibody, uTg maximum unstimulated $\mathrm{Tg}, R A /$ radioactive iodine, off-Tg Pre-RAl ablation serum-stimulated Tg, on- $\mathrm{Tg}$ unstimulated Tg detected at 1 week after RAl ablation 
Table 1 Characteristics of the patients $(\mathrm{N}=60)$

\begin{tabular}{|c|c|c|}
\hline Variable & $\mathrm{N}$ & $\%$ \\
\hline Ages, yrs, mean $\pm S D(I Q R)$ & $44.1 \pm 13.8(33-54)$ & - \\
\hline$\geq 45$ & 29 & 48.3 \\
\hline$\geq 55$ & 14 & 23.3 \\
\hline Sex, male/female & $18 / 42$ & $30.0 / 70.0$ \\
\hline $\mathrm{BMI}$ & $23.1 \pm 3.7$ & \\
\hline NG & 24 & 40.0 \\
\hline $\mathrm{HD}$ & 8 & 13.3 \\
\hline Hypertension & 5 & 8.3 \\
\hline Diabetes & 3 & 5.0 \\
\hline Hyperthyroidism & 5 & 8.3 \\
\hline Hypothyroidism & 0 & 0 \\
\hline \multicolumn{3}{|l|}{ Tumor size (primary), mm } \\
\hline Mean $\pm S D(I Q R)$ & $21.7 \pm 14.3(10.75-22.25)$ & \\
\hline$>40 \mathrm{~mm}$ & 7 & 11.7 \\
\hline Multifocality (primary) & 11 & 18.3 \\
\hline Bilaterality (primary) & 8 & 13.3 \\
\hline TgAb positive (> 115U/mL) & 8 & 13.3 \\
\hline \multicolumn{3}{|l|}{ TNM stage (primary) } \\
\hline $\mathrm{TX} / \mathrm{T} 1 / \mathrm{T} 2 / \mathrm{T} 3 / \mathrm{T} 4$ & $8 / 11 / 6 / 16 / 19$ & 13.3/18.3/10.0/26.7/31.7 \\
\hline Nx/N0/N1a/N1b & $0 / 11 / 12 / 37$ & 0/18.3/20.0/61.7 \\
\hline Mx/M0/M1 & $1 / 59 / 0$ & $1.7 / 98.3 / 0$ \\
\hline \multicolumn{3}{|l|}{ Surgical strategy } \\
\hline $\mathrm{iCND/bCND}$ & $4 / 15$ & $6.7 / 25.0$ \\
\hline$i C N D+i L N D$ & 7 & 11.7 \\
\hline$b C N D+i L N D$ & 24 & 40.0 \\
\hline $\mathrm{bCND}+\mathrm{bLND}$ & 10 & 16.7 \\
\hline Harvested LNs & $33.0 \pm 20.8$ & \\
\hline Metastatic LNs & $8.5 \pm 8.2$ & \\
\hline The ratio of metastatic LNs \% & $29.5 \pm 23.1$ & \\
\hline RAI Administration & 49 & 81.7 \\
\hline Central LNs recurrence & 19 & 31.7 \\
\hline Lateral LNs recurrence & 36 & 60.0 \\
\hline Central \& lateral LNs recurrence & 5 & 8.3 \\
\hline Diameters of recurrent LNs, mm, Mean $\pm S D(I Q R)$ & $18.7 \pm 12.9(10.75-22.00)$ & \\
\hline Extranodal extension & 20 & 33.3 \\
\hline
\end{tabular}

BMI Body Mass Index, HD Hashimoto's disease, NG nodular goiter, iCND ipsilateral central neck dissection, $b C N D$ bilateral central neck dissection, iLND ipsilateral lateral neck dissection, bLND bilateral lateral neck dissection, $L N$ lymph node

$(\mathrm{OR}=8.767 ; \quad 95 \% \quad \mathrm{CI}=1.392-55.216 ; \quad P=0.021)$, while multifocality was an independent protective factor for maximum $\mathrm{uTg} \geq 0.2 \mathrm{ng} / \mathrm{mL} \quad(\mathrm{OR}=0.123$; 95\% CI $=0.020-0.762 ; \quad P=0.024)$. As for patients received $\mathrm{RAI}$ with $\mathrm{TgAb}$-negative, the ratio of metastatic LNs $\geq 25 \%$ was an independent predictor for off$\mathrm{Tg} \geq 1 \mathrm{ng} / \mathrm{mL} \quad(\mathrm{OR}=20.997 ; 95 \% \mathrm{CI}=1.649-267.384$; $P=0.019)$. However, no significant differences were found in the multivariate analysis for predictors of on- $\mathrm{Tg} \geq 0.2 \mathrm{ng} / \mathrm{mL}$ (Table 5 ).

\section{Discussion}

We included PTC patients with recurrence of LNs and tried to find out the differences between Tg-negative or positive during the follow-up. Our current study cohort was well followed with a median period of 29 months but subjected by a notable sample size (60 patients). Though many PTC patients underwent secondary surgery for recurrence in our center, the primary treatment of partial them were performed elsewhere and it became difficult to obtain the whole and correct data. In order to ensure 
Table 2 Comparisons of maximum uTg with TgAb-negative

\begin{tabular}{|c|c|c|c|c|}
\hline & $\mathrm{uTg} \geq 0.2 \mathrm{ng} / \mathrm{ml}(\mathrm{N}=39)$ & $\mathrm{uTg}<0.2 \mathrm{ng} / \mathrm{ml}(\mathrm{N}=13)$ & $t / x^{2}$ & $P$ \\
\hline Age, yrs & $47.2 \pm 14.1$ & $39.2 \pm 12.1$ & -1.827 & 0.074 \\
\hline Sex (male) & 15 & 3 & 0.453 & 0.501 \\
\hline $\mathrm{BMI}$ & $23.7 \pm 3.9$ & $22.5 \pm 3.8$ & -0.938 & 0.353 \\
\hline NG & 16 & 6 & 0.105 & 0.746 \\
\hline $\mathrm{HD}$ & 5 & 1 & $<0.001$ & 1.000 \\
\hline Hypertension & 4 & 2 & $<0.001$ & 1.000 \\
\hline Diabetes & 2 & 1 & - & 1.000 \\
\hline Hyperthyroidism & 3 & 2 & 0.074 & 0.786 \\
\hline Tumor size (primary), mm & $21.7 \pm 13.3$ & $18.9 \pm 10.4$ & -0.682 & 0.498 \\
\hline Multifocality (primary) & 4 & 5 & 3.628 & 0.057 \\
\hline Bilatrality (primary) & 4 & 2 & $<0.001$ & 1.000 \\
\hline \multicolumn{5}{|l|}{ Surgical strategy } \\
\hline iCND & 2 & 1 & - & 1.000 \\
\hline$b C N D$ & 11 & 4 & - & 1.000 \\
\hline$b C N D+i L N D$ & 20 & 8 & - & 0.403 \\
\hline $\mathrm{bCND}+\mathrm{bLND}$ & 8 & 1 & - & 0.403 \\
\hline Harvested LNs & $32.7 \pm 21.6$ & $40.5 \pm 19.7$ & 1.148 & 0.256 \\
\hline Metastatic LNs & $9.6 \pm 8.8$ & $5.9 \pm 7.3$ & -1.356 & 0.181 \\
\hline The ratio of metastatic LNs \% & $34.1 \pm 25.7$ & $14.4 \pm 10.5$ & -3.900 & $0.001^{*}$ \\
\hline Diameter of recurrent LNs & $21.1 \pm 14.7$ & $14.6 \pm 5.6$ & -2.279 & $0.027^{*}$ \\
\hline$\geq 25 \mathrm{~mm}$ & 13 & 0 & 5.778 & $0.023^{*}$ \\
\hline Extranodal extension & 15 & 5 & $<0.001$ & 1.000 \\
\hline
\end{tabular}

BMI Body Mass Index, HD Hashimoto's disease, NG nodular goiter, iCND ipsilateral central neck dissection, $b C N D$ bilateral central neck dissection, iLND ipsilateral lateral neck dissection, $b L N D$ bilateral lateral neck dissection, $L N s$ lymph nodes

*Means significantly statistical differences

the integrality and avoid the bias coming from incomplete outcomes, we decided to establish strict inclusive criteria other than simply enlarging the sample size. It was recognized that positive $\mathrm{TgAb}$ levels would affect the serum Tg levels and some studies excluded all patients with $\mathrm{TgAb}$-positive to avoid potential interference $[7,13]$. The recent study concluded that $\mathrm{TgAb}$ interference limits $\mathrm{Tg}$ utility as a tumor marker in $30 \%$ of $\mathrm{TgAb}$-positive patients [14]. However, we did not exclude patients with $\mathrm{TgAb}$-positive in our study because we found the serum $\mathrm{Tg}$ levels of the patients with $\mathrm{TgAb}$-positive were far from the threshold and the interference of TgAb levels would not affect the results of the grouping. Nevertheless, to ensure the most preciseness, subgroup excluding patients with $\mathrm{TgAb}$-positive was still conducted.

Our results indicated that patients with maximum $\mathrm{uTg} \geq 0.2 \mathrm{ng} / \mathrm{mL}$ were significantly associated with older age, diameters of recurrent $\mathrm{LNs} \geq 25 \mathrm{~mm}$ and higher LNs metastatic rate at primary surgery. Age is often associated with tumor malignancy and 55 years old is regarded as a cut-off age in the $8^{\text {th }}$ edition AJCC staging system [11]. However, age was no longer an independent predictor when we excluded patients with $\mathrm{TgAb}$-positive. Higher metastatic rates seen in the maximum $\mathrm{uTg} \geq 0.2 \mathrm{ng} /$ $\mathrm{mL}$ group further indicated tumor malignancy and invasiveness.

Positive off-Tg levels and positive on-Tg levels were significantly associated with a larger diameter of recurrent LNs. The sources of Tg were recurrent LNs and the levels of $\mathrm{Tg}$ theoretically depended on numbers of recurrent LNs and size of each recurrent LNs when there were no other remnant areas, and the levels of $\mathrm{Tg}$ were also regulated by TSH levels. No difference of numbers of metastatic LNs and TSH levels was found when performing the analysis of positive and negative groups of off-Tg or on-Tg. This similar trend was observed when comparing maximum uTg-positive group and maximum uTg-negative group in all included patients. This might be due to the large proportion of RAI patients (81.7\%) which add to this trend and possibly existed remnant thyroid or tumor tissues in patients without RAI administration shared the source which finally led to no difference. RAI administration was considered the effective way to ablate remnant thyroid tissue though incomplete structural response sometimes occurred [15]. 
Table 3 Comparisons of Off-Tg with TgAb-negative and RAI administration

\begin{tabular}{|c|c|c|c|c|}
\hline & Off-Tg $\geq 1 \mathrm{ng} / \mathrm{ml}(\mathrm{N}=33)$ & Off-Tg $<1 \mathrm{ng} / \mathrm{ml}(\mathrm{N}=10)$ & $t / x^{2}$ & $P$ \\
\hline Age, yrs & $46.2 \pm 14.3$ & $38.4 \pm 16.0$ & -1.478 & 0.147 \\
\hline Sex (male) & 13 & 3 & 0.027 & 0.869 \\
\hline $\mathrm{BMI}$ & $23.4 \pm 3.5$ & $22.5 \pm 3.3$ & -0.776 & 0.442 \\
\hline NG & 16 & 3 & 0.446 & 0.504 \\
\hline $\mathrm{HD}$ & 4 & 1 & $<0.001$ & 1.000 \\
\hline Hypertension & 3 & 1 & - & 1.000 \\
\hline Diabetes & 1 & 1 & - & 0.415 \\
\hline Hyperthyroidism & 0 & 2 & - & 1.000 \\
\hline Tumor size (primary), mm & $22.7 \pm 14.0$ & $18.7 \pm 11.0$ & -0.829 & 0.412 \\
\hline Multifocality (primary) & 3 & 4 & 3.351 & 0.067 \\
\hline Bilatrality (primary) & 3 & 1 & - & 1.000 \\
\hline \multicolumn{5}{|l|}{ Surgical strategy } \\
\hline $\mathrm{iCND}$ & 0 & 0 & - & - \\
\hline$b C N D$ & 7 & 2 & - & - \\
\hline$b C N D+i L N D$ & 19 & 7 & - & 0.645 \\
\hline$b C N D+b L N D$ & 7 & 1 & - & 0.645 \\
\hline Harvested LNs & $37.6 \pm 20.8$ & $38.2 \pm 21.8$ & 0.074 & 0.941 \\
\hline Metastatic LNs & $10.3 \pm 9.2$ & $6.8 \pm 8.2$ & -1.079 & 0.287 \\
\hline The ratio of metastatic LNs \% & $29.8 \pm 23.6$ & $16.3 \pm 10.7$ & -1.744 & 0.089 \\
\hline Diameter of recurrent LNs & $23.0 \pm 15.0$ & $15.6 \pm 4.7$ & -2.472 & $0.018^{*}$ \\
\hline$\geq 25 \mathrm{~mm}$ & 13 & 0 & 3.933 & $0.047^{*}$ \\
\hline Extranodal extension & 11 & 6 & 1.304 & 0.254 \\
\hline
\end{tabular}

BMI Body Mass Index, HD Hashimoto's disease, NG nodular goiter, iCND ipsilateral central neck dissection, $b C N D$ bilateral central neck dissection, iLND ipsilateral lateral neck dissection, $b L N D$ bilateral lateral neck dissection, LNs lymph nodes

*Means significantly statistical differences

Off-Tg testing is recommended to obtain the best follow-up accuracy for recurrent or persistent disease detection than on- $T g$ [16]. In the multivariate analysis, a ratio of metastatic $\mathrm{LNs} \geq 25 \%$ was the only independent predicator for off- $\mathrm{Tg} \geq 1 \mathrm{ng} / \mathrm{mL}$, whereas no predicator was found in on $-\mathrm{Tg} \geq 0.2 \mathrm{ng} / \mathrm{mL}$. A recent study showed an initial off-Tg level of $5.0 \mathrm{ng} / \mathrm{mL}$ was involved in predicting recurrence with the highest sensitivity and specificity [7]. This is consistent with the results of a previous study, which defined the cut-off point for positive or negative value at $4.2 \mathrm{ng} / \mathrm{mL}$ [17]. However, off- $\mathrm{Tg}<1 \mathrm{ng} / \mathrm{mL}$ was considered negative in our analysis for a recent study suggested that off$\mathrm{Tg}$ levels were correlated with structural incomplete response: $0 \%$ structural incomplete response with the off-Tg levels of $<1 \mathrm{ng} / \mathrm{mL}, 1.73 \%$ with the off-Tg levels of $1-10 \mathrm{ng} / \mathrm{mL}$, and $42.74 \%$ with the off-Tg levels of $>10 \mathrm{ng} / \mathrm{mL}$, which corresponded to the guideline $(2015)[1,6]$. Orlov et al. proposed that patients with an off- $\mathrm{Tg}<1 \mathrm{ng} / \mathrm{mL}$ should not receive RAI and those with off-Tg 1-5 $\mathrm{ng} / \mathrm{mL}$ should be further evaluated based on repeat off-Tg levels and pathologic features [18]. However, the proportion $(10 / 43,23.3 \%)$ of patients with
off-Tg negative $(<1 \mathrm{ng} / \mathrm{mL})$ was not low as expected in patients with LNs recurrence. Thus, we thought the cut-off value of off-Tg in patients with risk of structural recurrence should be further discussed. Meanwhile, number of metastatic LNs $\geq 8$ showed an independent indicator for maximum $\mathrm{uTg} \geq 0.2 \mathrm{ng} / \mathrm{mL}$. Alexandria et al. similarly proposed a strategy to use maximum uTg levels for clinical decision making rather than off$\mathrm{Tg}$ levels [15]. Patients with maximum $\mathrm{uTg} \geq 0.2 \mathrm{ng} /$ $\mathrm{mL}$ did benefit from RAI administration as it effectively ablates remnant thyroid tissue, which might allow for easier biomedical detection of recurrence [15]. Our results suggested patients with maximum uTg $<0.2 \mathrm{ng} /$ $\mathrm{mL}$ have already achieved an excellent response from surgery with similar number of harvested LNs and lower ratio of metastatic LNs but still required attention on imaging during follow-up.

Our analysis did have limitations inherent in its study design. The data were retrospectively collected. In addition, a lot of patients were excluded for incomplete data of $\mathrm{Tg}$ and primary surgery, thus leading to the not notable sample size. We only focused on LNs recurrence, and other types of recurrence such as distant recurrence and 
Table 4 Comparisons of on-Tg with TgAb-negative and RAI administration

\begin{tabular}{|c|c|c|c|c|}
\hline & $\begin{array}{l}\text { On- } \\
\mathrm{Tg} \geq 0.2 \mathrm{ng} / \\
\mathrm{ml}(\mathrm{N}=30)\end{array}$ & $\begin{array}{l}\text { On- } \\
\mathrm{Tg}<0.2 \mathrm{ng} / \\
\mathrm{ml}(\mathrm{N}=13)\end{array}$ & $t / x^{2}$ & $P$ \\
\hline Age, yrs & $47.2 \pm 14.5$ & $38.0 \pm 14.2$ & -1.917 & 0.062 \\
\hline Sex (male) & 12 & 4 & 0.054 & 0.817 \\
\hline BMI & $23.4 \pm 3.5$ & $22.9 \pm 3.3$ & -0.417 & 0.679 \\
\hline$N G$ & 13 & 6 & 0.029 & 0.864 \\
\hline $\mathrm{HD}$ & 4 & 1 & $<0.001$ & 0.990 \\
\hline Hypertension & 3 & 1 & $<0.001$ & 1.000 \\
\hline Diabetes & 1 & 1 & - & 0.518 \\
\hline Hyperthyroidism & 2 & 0 & - & 1.000 \\
\hline $\begin{array}{l}\text { Tumor size (primary), } \\
\text { mm }\end{array}$ & $22.6 \pm 14.0$ & $19.9 .0 \pm 11.8$ & -0.594 & 0.556 \\
\hline Multifocality (primary) & 2 & 5 & 4.597 & $0.032^{*}$ \\
\hline Bilatrality (primary) & 2 & 2 & 0.110 & 0.740 \\
\hline \multicolumn{5}{|l|}{ Surgical strategy } \\
\hline iCND & 0 & 0 & - & - \\
\hline bCND & 6 & 3 & - & - \\
\hline$b C N D+i L N D$ & 17 & 9 & - & 0.385 \\
\hline$b C N D+b L N D$ & 7 & 1 & - & 0.385 \\
\hline Harvested LNs & $38.4 \pm 20.5$ & $36.3 \pm 22.3$ & -0.300 & 0.766 \\
\hline Metastatic LNs & $10.9 \pm 9.4$ & $6.2 \pm 7.4$ & -1.588 & 0.120 \\
\hline $\begin{array}{l}\text { The ratio of metastatic } \\
\text { LNs } \%\end{array}$ & $29.9 \pm 24.0$ & $19.1 \pm 14.4$ & -1.500 & 0.141 \\
\hline $\begin{array}{l}\text { Diameter of recurrent } \\
\text { LNs }\end{array}$ & $23.6 \pm 15.5$ & $16.0 \pm 4.7$ & -2.438 & $0.020^{*}$ \\
\hline$\geq 25 \mathrm{~mm}$ & 13 & 0 & 6.151 & $0.013^{*}$ \\
\hline Extranodal extension & 11 & 6 & 0.341 & 0.559 \\
\hline
\end{tabular}

BMI Body Mass Index, HD Hashimoto's disease, NG nodular goiter, iCND ipsilateral central neck dissection, $b C N D$ bilateral central neck dissection, iLND ipsilateral lateral neck dissection, $b L N D$ bilateral lateral neck dissection, LNs lymph nodes

*Means significantly statistical differences

Table 5 Multivariate analysis of predictors of maximum uTg $\geq 0.2 \mathrm{ng} / \mathrm{mL}$ with TgAb-negative

\begin{tabular}{|c|c|c|c|}
\hline & $P$ & OR & $95 \% \mathrm{Cl}$ \\
\hline Multifocality & $0.024^{*}$ & 0.123 & $0.020-0.762$ \\
\hline $\begin{array}{l}\text { Number of metastatic } \\
L N s \geq 8\end{array}$ & $0.021^{*}$ & 8.767 & $1.392-55.216$ \\
\hline
\end{tabular}

$O R$ odds ratio, $C l$ confidence interval, $L N$ s lymph nodes

${ }^{*}$ Means significantly statistical differences

biochemical recurrence were not analyzed. The accurate time of the recurrent was difficult to decide.

\section{Conclusions}

This study found $\mathrm{Tg}$-positive was associated with larger size of recurrent LNs. Number of metastatic LNs $\geq 8$ could independently predict maximum uTg-positive with negative $\operatorname{TgAb}$ levels. The ratio of metastatic $\mathrm{LNs} \geq 25 \%$ was an independent predictor for off-Tg-positive in patients with negative TgAb levels and RAI administration. RAI administration seems to benefit the value of $\mathrm{Tg}$ measurement during follow-up. However, importantly, imaging examinations need to be further applied for $\mathrm{Tg}$ negative patients on account of difficulty on detecting $\mathrm{Tg}$ with smaller LNs, especially for patients without RAI ablation.

\section{Abbreviations}

Tg: Serum thyroglobulin; PTC: Papillary thyroid carcinoma; LNs: Lymph nodes; TT: Total thyroidectomy; RAl: Radioactive iodine; uTg: Unstimulated Tg; off-Tg: Pre-RAl ablation serum-stimulated Tg; on-Tg: Unstimulated Tg detected at 1 week after RAl ablation; CND: Central neck dissection; LND: Lateral neck dissection; TgAb: Anti-thyroglobulin antibody; TSH: Thyroid stimulating hormone; BMI: Body mass index; NG: Nodular goiter; HD: Hashimoto's thyroiditis; ROC: Receiver operator characteristic; OR: Odds ratio; Cl: Confidence interval.

\section{Acknowledgements}

The authors thank the entire staff of the participating departments for their expert assistance and the American Journal Experts (AJE) for the professional language editing.

\section{Authors' contributions}

$Z X$ and $Y Q$ designed this study. ZX, YQ, ZL, LZ, and YF were responsible for data collection. ZL, LZ, YF were responsible for analysis and interpretation of the data. ZX and YQ participated in the analysis of data and drafted the manuscript. JZ and AS contributed to the conception and design of the study and revision of the manuscript. All authors read and approved the final manuscript.

\section{Funding}

None.

\section{Availability of data and materials}

Datasets from the current study are available from the corresponding author on reasonable request.

\section{Ethics approval and consent to participate}

This study was in accordance with the Declaration of Helsinki and has been approved by the ethics committee of West China Hospital, Sichuan University.

\section{Consent for publication}

Not applicable.

\section{Competing interests}

All authors report no conflicts of interest in this work.

\section{Author details}

${ }^{1}$ Center of Thyroid \& Parathyroid Surgery, West China Hospital, Sichuan University, NO. 37 Guo Xue Xiang, Chengdu, Sichuan, People's Republic of China. ${ }^{2}$ Department of Ultrasound, West China Hospital, Sichuan University, NO. 37 Guo Xue Xiang, Chengdu, China.

Received: 10 June 2020 Accepted: 14 January 2021

Published online: 22 January 2021

\section{References}

1. Haugen BR, Alexander EK, Bible KC, Doherty GM, Mandel SJ, Nikiforov YE, Pacini F, Randolph GW, Sawka AM, Schlumberger M, et al. 2015 American thyroid association management guidelines for adult patients with thyroid nodules and differentiated thyroid cancer: the American Thyroid 
Association Guidelines task force on thyroid nodules and differentiated thyroid cancer. Thyroid. 2016;26(1):1-133.

2. Eskander A, Merdad M, Freeman JL, Witterick IJ. Pattern of spread to the lateral neck in metastatic well-differentiated thyroid cancer: a systematic review and meta-analysis. Thyroid. 2013;23(5):583-92.

3. Sywak M, Cornford L, Roach P, Stalberg P, Sidhu S, Delbridge L. Routine ipsilateral level VI lymphadenectomy reduces postoperative thyroglobulin levels in papillary thyroid cancer. Surgery. 2006;140(6):1000-5.

4. Ito Y, Kudo T, Takamura Y, Kobayashi K, Miya A, Miyauchi A. Lymph node recurrence in patients with $\mathrm{N} 1 \mathrm{~b}$ papillary thyroid carcinoma who underwent unilateral therapeutic modified radical neck dissection. World J Surg. 2012;36(3):593-7.

5. Giovanella L, Ceriani L, Maffioli M. Postsurgery serum thyroglobulin disappearance kinetic in patients with differentiated thyroid carcinoma. Head Neck. 2010;32(5):568-71.

6. Yang X, Liang J, Li T, Zhao T, Lin Y. Preablative stimulated thyroglobulin correlates to new therapy response system in differentiated thyroid cancer. J Clin Endocrinol Metab. 2016;101(3):1307-13.

7. Lee SH, Roh JL, Gong G, Cho KJ, Choi SH, Nam SY, Kim SY. Risk factors for recurrence after treatment of $\mathrm{N} 1 \mathrm{~b}$ papillary thyroid carcinoma. Ann Surg. 2019;269(5):966-71.

8. Cortes MCS, Rosario PW, Oliveira LFF, Calsolari MR. Clinical impact of detectable antithyroglobulin antibodies below the reference limit (borderline) in patients with papillary thyroid carcinoma with undetectable serum thyroglobulin and normal neck ultrasonography after ablation: a prospective study. Thyroid. 2018;28(2):229-35.

9. Webb RC, Howard RS, Stojadinovic A, Gaitonde DY, Wallace MK, Ahmed J, Burch HB. The utility of serum thyroglobulin measurement at the time of remnant ablation for predicting disease-free status in patients with differentiated thyroid cancer: a meta-analysis involving 3947 patients. J Clin Endocrinol Metab. 2012:97(8):2754-63.

10. Bachelot A, Leboulleux S, Baudin E, Hartl DM, Caillou B, Travagli JP, Schlumberger M. Neck recurrence from thyroid carcinoma: serum thyroglobulin and high-dose total body scan are not reliable criteria for cure after radioiodine treatment. Clin Endocrinol. 2005;62(3):376-9.

11. Zanoni DK, Patel SG, Shah JP. Changes in the 8th edition of the American Joint Committee on Cancer (AJCC) staging of head and neck cancer: rationale and implications. Curr Oncol Rep. 2019;21(6):52.
12. Denaro N, Merlano MC, Russi EG. Follow-up in head and neck cancer: do more does it mean do better? A systematic review and our proposal based on our experience. Clin Exp Otorhinolaryngol. 2016;9(4):287-97.

13. Kim TY, Kim WB, Kim ES, Ryu JS, Yeo JS, Kim SC, Hong SJ, Shong YK. Serum thyroglobulin levels at the time of 1311 remnant ablation just after thyroidectomy are useful for early prediction of clinical recurrence in low-risk patients with differentiated thyroid carcinoma. J Clin Endocrinol Metab. 2005;90(3):1440-5.

14. Algeciras-Schimnich A. Thyroglobulin measurement in the management of patients with differentiated thyroid cancer. Crit Rev Clin Lab Sci. 2018;55(3):205-18.

15. McDow AD, Shumway CM, Pitt SC, Schneider DF, Sippel RS, Long KL. Utility of early postoperative unstimulated thyroglobulin in influencing decision making in patients with papillary thyroid carcinoma. Ann Surg Oncol. 2019;26(12):4002-7.

16. Eustatia-Rutten CF, Smit JW, Romijn JA, van der Kleij-Corssmit EP, Pereira AM, Stokkel MP, Kievit J. Diagnostic value of serum thyroglobulin measurements in the follow-up of differentiated thyroid carcinoma, a structured meta-analysis. Clin Endocrinol (Oxf). 2004;61 (1):61-74.

17. Kim SJ, Park SY, Lee YJ, Lee EK, Kim SK, Kim TH, Jung YS, Ryu J, Myong JP, Chung KW. Risk factors for recurrence after therapeutic lateral neck dissection for primary papillary thyroid cancer. Ann Surg Oncol. 2014;21(6):1884-90

18. Orlov S, Salari F, Kashat L, Freeman JL, Vescan A, Witterick IJ, Walfish PG. Post-operative stimulated thyroglobulin and neck ultrasound as personalized criteria for risk stratification and radioactive iodine selection in low- and intermediate-risk papillary thyroid cancer. Endocrine. 2015;50(1):130-7.

\section{Publisher's Note}

Springer Nature remains neutral with regard to jurisdictional claims in published maps and institutional affiliations.
Ready to submit your research? Choose BMC and benefit from:

- fast, convenient online submission

- thorough peer review by experienced researchers in your field

- rapid publication on acceptance

- support for research data, including large and complex data types

- gold Open Access which fosters wider collaboration and increased citations

- maximum visibility for your research: over 100M website views per year

At BMC, research is always in progress.

Learn more biomedcentral.com/submissions 